\title{
Major depressive disorder in different age groups and quality of life
}

\author{
Umme Salma Talukder, ${ }^{1}$ MM Jalal Uddin, ${ }^{2}$ Niaz Mohammad Khan, ${ }^{3}$ Md Mostarshid Billah, ${ }^{4}$ Tufayel \\ Ahmed Chowdhury, ${ }^{5}$ Md Faruq Alam, ${ }^{6}$ Md Shah Alam $^{7}$
}

${ }^{1}$ Assistant Professor, Department of Psychiatry, Bangladesh Institute of Research and Rehabilitation in Diabetes, Endocrine and Metabolic Disorders (BIRDEM), Shahbag, Dhaka, Bangladesh, ${ }^{2}$ Assistant Professor; Department of Psychiatry, National Institute of Neurosciences and Hospital (NINSH), Dhaka, Bangladesh; ${ }^{3}$ Assistant Professor (Psychiatry), Officer on Special Duty, Directorate General of Health Services, Dhaka, Bangladesh; ${ }^{4}$ Assistant Professor, Department of Nephrology and Dialysis, BIRDEM, Dhaka, ${ }^{5}$ Registrar, Department of Nephrology, BIRDEM, Dhaka, Bangladesh; ${ }^{6}$ Professor of Child, Adolescent and Family psychiatry, NIMH, Dhaka, Bangladesh, 'Professor and Head, Department of Psychiatry, Popular Medical College, Dhaka, Bangladesh.

Article info
Received: 04 April 2016
Accepted : 01 Sept 2016
Number of tables : 02
Number of figures : 00
Number of refs. : 22
Correspondence:
Umme Salma Talukder
Mobile: +8801757321999,
E-mail: safiy3@gmail.com

\section{Article info}

Received: 04 April 2016

Accepted : 01 Sept 2016

Number of tables : 02

Number of figures : 00

Number of refs. : 22

\begin{abstract}
Summary:
Major Depressive Disorder (MDD) is a significant public health problem due to its impact on the quality of life. The aim of the study was to determine the presentation of depression in different age group and quality of life among the respondents. This was a descriptive cross sectional study conducted from May, 2012 to February, 2013 among 65 patients aged 18 to 65 years with major depressive disorder in both outpatient and inpatient departments of National Institute of Mental Health (NIMH), Dhaka by using convenient sampling technique. Diagnostic and Statistical Manual of Mental DisordersText version (DSM-IV-TR), Beck Depression Inventory and World Health Organization Quality of Life Scale, Brief version (WHOQOL-BREF) were used to diagnose depressive disorder, to measure severity of depressive illness and Quality of Life (QOL) respectively. Level of depression was compared with the QOL. Quality of life deteriorated in patients with depression. Presence and level of depression was compared in different age groups of depressed patients. The results showed that most of the depressed people (17) were found in the age group of 21-25 years and most of the patients were severely depressed which was thirty nine (39). The study revealed that young people were mostly depressed and their quality of life was decreasing. It needs further study to explore more information about pattern of presentation of depression and its effect on the quality of life.
\end{abstract}

Bang J Psychiatry 2014,28(2):58-61

\section{Introduction}

Although Major Depressive Disorder (MDD) is associated with significant impairment in Health-Related Quality of Life (HRQOL), few studies have evaluated HRQOL dysfunction in multiple domains. ${ }^{1}$ An important correlation of functioning is Quality of Life (QOL), which is typically defined as patients own assessment of how they feel about what they have, how they are functioning and their ability to derive pleasure from their activities. ${ }^{2}$ Researchers in the University of Toronto defined Quality of Life (QOL) as "the degree to which a person enjoys the important possibilities of his or her life. ${ }^{3}$ Major depressive disorder affecting all ages including the young adults demanding special attention towards the illness in context to management and productivity. ${ }^{4}$ The prevalence of depression in Bangladesh is $6.4 \%$ and by 2020 it will be the $2^{\text {nd }}$ most disease burden worldwide. $^{5-6}$ Therefore the significant deterioration of quality of life of Bangladeshi people having a profound effect on disease burden needs to be measured. So, on this background the current study was aimed to find out the presentation of depressive disorder in different age group and the quality of life among them.

\section{Materials and methods}

This was a descriptive cross-sectional study done from May, 2012 to February, 2013 at the National institute of Mental Health (NIMH), Dhaka, Bangladesh. Both inpatients and outpatients were taken. The sample size was 65 . The study population was people with depressive disorder between ages 18 to 65 years. Inclusion criteria were diagnosed depressive disorder patients in the age range of $18-65$ years. The patients with major depressive disorder due to general medical conditions, substance related mood disorder or substance induced mood disorder, dysthymia and cyclothymia were excluded. Major depressive disorder was diagnosed with the criteria in Diagnostic and 
Statistical Manual of Mental Disorders-text version, fourth edition (DSM-IV). ${ }^{7}$ Beck Depression Inventorya was used to measure severity of depressive disorder and World Health Organisation Quality of Life Scale, brief version (WHOQOL-BREF) was used to measure Quality of Life (QOL). ${ }^{5}$

\section{Results}

Table 1 showed that among the respondents, 6 persons had a QOL score of 70, 8 persons had score of 70.48 , 12 had a score of 74.5 and 39 (most of the participants) had a score of 79.6. Table 2 showed the total number of patients was 65 . In the age group below 20, minimal and mild depression was not present. There was 1 case with moderate depression and 3 cases with severe depression. The total number of patients were 17 and 9 patients were severely depressed. The number of minimally and moderately depressed patients was 2, 3 patients were moderately depressed and 10 had severe depression. In the age group of 31-35 years, 1 had minimal and 1 had moderate depression and 5 were severely depressed. There were 4 patients in the 41-45 years age group, 1 was moderately depressed and 3 were severely depressed. 1 patient among 51-55 years age groups was severely depressed. 6 samples were found in the 56-60 years age group, 2 patients were mildly, 1 patient was moderately and 3 patients were severely depressed. From 61-65 years 4 patients were severely depressed. 1 patient was minimally and 2 were moderately depressed.

Table 1: Severity of depression and the corresponding QOL $(n=65)$

\begin{tabular}{lccc}
\hline Severity & Frequency & Percentage (\%) & QOL score \\
\hline Minimal & 6 & 9.2 & 70 \\
Mild & 8 & 12.3 & 70.48 \\
Moderate & 12 & 18.5 & 74.5 \\
Severe & 39 & 60 & 79.6 \\
\hline
\end{tabular}

Table 2: Distribution of age group and BDI score of the respondents $(n=65)$

\begin{tabular}{lccccc}
\hline $\begin{array}{l}\text { Age Group } \\
\text { (yrs) }\end{array}$ & $\begin{array}{c}\text { Minimal } \\
(\mathbf{0 - 1 3 )}\end{array}$ & $\begin{array}{c}\text { Mild } \\
(\mathbf{1 4}-19)\end{array}$ & $\begin{array}{c}\text { Moderate } \\
(\mathbf{2 0 - 2 8})\end{array}$ & $\begin{array}{c}\text { Severe } \\
(\mathbf{2 9 - 3 6 )}\end{array}$ & \\
\hline 20 and below & 0 & 0 & 1 & 3 & 4 \\
$21-25$ & 2 & 2 & 3 & 10 & 17 \\
$26-30$ & 0 & 1 & 1 & 9 & 11 \\
$31-35$ & 1 & 0 & 1 & 5 & 7 \\
$36-40$ & 1 & 1 & 1 & 5 & 8 \\
$41-45$ & 0 & 1 & 0 & 3 & 4 \\
$46-50$ & 1 & 0 & 2 & 0 & 3 \\
$51-55$ & 0 & 0 & 0 & 1 & 1 \\
$56-60$ & 0 & 2 & 1 & 3 & 6 \\
$61-65$ & 1 & 1 & 2 & 0 & 4 \\
\hline Total & 6 & 8 & 12 & 39 & 65 \\
\hline
\end{tabular}

\section{Discussion}

To measure the quality of life of patients suffering from major depressive disorder a cross sectional study was done on 65 patients attending National Institute of Mental Health, Dhaka. Severity of major depressive disorder was measured by Beck Depression inventory $2^{\text {nd }}$ edition and World Health Organization Quality of Life (WHO-QOL) scale was used to measure the quality of life. ${ }^{4-5}$ Minimally depressed patients had a quality of life (WHO-QOL) which scored 70. Mild depression showed a score of 70.48 , moderate depression showed 74.5 and severe major depressive disorder had a score of 79.6. In our study the QOL was proportional to the level of depression. QOL score increased as the depressive illness increased in severity. Similar studies suggested that even moderate level of major depressive disorder affected quality of life. ${ }^{9}$ This study coincided with other studies that individuals with mild levels of depressive symptoms had worse functioning than individuals who reported no symptoms. ${ }^{10}$ In a study abroad individual with moderate to severe symptoms had worse functioning than individuals who reported mild levels of depression. ${ }^{11}$ There is disparity in findings in this study compared with others. However, as yet no population norms have been published as a reference point against which researchers can interpret their findings. This study provided preliminary population norms for this purpose, especially this was the very first attempt undertaken to compare QOL and the level of depression. Randomly sampled community residents from two studies were pooled and used to examine the properties of the WHOQOL-BREF by age group, gender and health status. The results showed that general norms for the WHOQOL-BREF domains were $73.5(S D=18.1)$ for the physical health domain, 70.6 (14.0) for wellbeing, psychological 71.5 (18.2) for social relationships and 75.1 (13.0) for the environment domain. In general, scores declined slightly by age group. For females scores were stable across the lifespan with an accelerated decline after the age of 60 years. Males exhibited a more consistent and even decline across the lifespan. There were significant differences in WHOQOL-BREF scores when reported by health status, with those in poor health obtaining scores that were up to $50 \%$ lower than those in excellent health. Effect sizes between different health status levels were reported. ${ }^{12}$ Here, preliminary norms and effect sizes may be used as reference points for interpreting WHOQOL-BREF scores. They provided additional information to the numerous studies already reporting on the validity of the WHOQOL-BREF. The scoring of the WHO-QOL has reciprocal relationship with the severity of depression. Usually the QOL decreases with the depression severity. ${ }^{12}$ In this study, the scores of QOL increased with the severity of depression. This was due to the very characteristics of the patients interviewed who were mostly females from 
illiterate and low socio-economic group. These patients usually responded in affirmative in every question without understanding the questions clearly. Moreover, they usually thought it wise and less embarrassing to hide painful facts of their lives regarding emotion and sexual life. They would rather say things were "OK", giving unauthentic answers. In addition to that as depression increased in severity the patient would be more reluctant to understand and answer the question. This again made the scoring more difficult in severe depression. In spite of everything the scoring was done entirely depending on the patients self-rating answers. Very little researches were done on QOL of depressive patients and the effect of clinical depression on QOL. Therefore it was difficult to set a standard value on the relationship of BDI scoring and WHO-QOL scoring. Some study findings demonstrated a clear incremental worsening of functioning with increasing severity of depressive symptoms. ${ }^{12}$ In another study similar results showed that chronic dysthymia was associated with poorer HRQOL. Quality of life also progressively decreased for major depressive disorder the high prevalence of disorder, $30 \%$ of individuals diagnosed with depressive illness experience a relapse within three months and in the absence of continued treatment, $50 \%$ of those with depression will experience another episode within two years. ${ }^{13}$ Depressive illnesses have a substantially lower QOL than healthy subjects and QOL was severely affected by a number of life domains. ${ }^{9}$ Measurements of quality of life were also done on other several diseases, for example breast cancer survivors colorectal cancer etc. where QOL was impaired. ${ }^{14-17}$ In a study on breast cancer, most participants reported mild-tomoderate levels of fatigue and pain. It was found that $21 \%$ percent and $36 \%$ of patients might have had an anxiety and depressive disorder respectively. Significant correlations among the four symptoms supported the existence of the symptom cluster. The participants receiving chemotherapy with inadequate social support, experienced higher levels of symptoms and were more likely to have a poorer QOL. ${ }^{14}$ Data also confirmed that QOL was markedly reduced in Chronic Idiopathic Urticaria (CIU) patients. Physical health and psychological health were found to be the areas QOL most affected in CIU patients. We also have found that CIU patients frequently suffered from depression and anxiety. ${ }^{18}$ The severity of these parameters were found to be positively correlated with the extent of QOL decrease. QOL has been studied in different medical and psychiatric diseases like chronic renal failure, cancer, ICU patients. ${ }^{15-20}$ schizophrenia, ${ }^{21}$ Obsessive compulsive disorder (OCD), ${ }^{20}$ but no research compared level of depression with quality of life. Bulk of the patients (39) was severely depressed. Least number of patients (6) were minimally depressed. 12 patients were moderately and 8 were mildly depressed. Population at the earlier ages, which was from 18-20 years showed least appearances of depression. The greatest sample size represented age group of 21-25 years which were 17 subjects; the second larger populations diagnosed with major depressive disorder were 11 in the age group 26-30 years. Only 1 patient was found in 51-55 years group and the patient was severely depressed. Depression declined progressively over the years. These findings were consistent with the latest reports that depression affected all age group. The percentage of depression in general population was $4.6 \% .^{5}$ This study was an alarming indication that depressive disorder an incapacitating disease affecting the most potentially productive age group which is $20-30$ years. Most severely depressed ${ }^{20}$ patients (10) were found in the age group 21-25 years. In a study, carried out in Bangladesh, it was found that major depressive disorder was most prevalent in 20-40 years of age group. ${ }^{17}$ Depressive disorder can occur in any age group. ${ }^{4}$ But it was most common in 20-40 years age group. ${ }^{5}$ These statistics was alarming because people with the most potential and in the reproductive age group were being depressed. Moreover the level of depression was also more severe in this group. People in the older age group were also found, but they were less in proportion and severity, one reason for this was that they have fully developed defense mechanism and can handle their depression better with fewer reports to the clinician. Factors like academic stress, less job opportunity, unemployment, drug abuse, teenage marriage, inadequate scope for higher education, political violence etc. were contributing to the high prevalence of depression of young adults. Thirty- nine people, which were the majority of the sample, were severely depressed indicating unawareness of the general people of our country regarding depressive illness and its treatment. That was why they wait till the disease becomes too incapacitating, before reporting to the hospital. Depression is now the fourth leading cause of global disease burden and will be the second most global burden of disease in 2020 according to WHO reports. It is also the leading cause of disability worldwide. ${ }^{20-22}$

\section{Conclusion}

Quality of life is an important tool for assessing the effect of depression in functioning of the patients. This study will provide important guideline in approaching people suffering from major depressive disorder regarding age distribution and their qualityof life.

\section{References}

1. Saarni SI, Suvisaari J. Impact of psychiatric disorders on health related quality of life; general population survey. Br J Psychiatry 2007;190:32632.

2. Gregory D, Johnston R, Pratt G, Watts $M$, Whatmore $S$. The dictionary of human geography. Oxford: Willey-Blackwell; 2009.

3. Ishak WW, Balayan K, Bresee C, Greenberg JM, Fakhry $\mathrm{H}$, Christensen $\mathrm{S}$, et al. A descriptive analysis of quality of life 
of using patient reported measures in major depressive disorders in naturalistic outpatient settings. Qual Life Res 2013;29;22(3):585-96.

4. Gelder M, Harrison P, Cowen P. Shorter oxford textbook of psychiatry. 5th ed. Oxford: Oxford University Press; 2006.

5. Firoz AHM, Karim ME, Alam MF, Rahman AHMM, Zaman MM, Rabbani MG, et al. Awareness, care and acceptance of mental patients: a nationwide multicentric community survey in Bangladesh. Bang $\mathrm{J}$ Psychiatry 2009;1(1):9-30.

6. World Health Organization. Quality of Life Scale WHOQOL-BREF, introduction administration scoring and generic version of assessment. Geneva: World Health Organization; 1996.

7. American Psychiatric Association. Diagnostic and statistical manual of mental disorders. 4th ed. Washington DC: American Psychiatric Press; 1994.

8. Beck AT, Steer RA, Brown GK. Manual for the Beck depression inventory-II. San Antonio, TX: Psychological Corporation; 1996.

9. Gretchen A, Brenes. Psychiatry and behavioural medicine and social sciences and health policy. North Carolina: Wake Forest university school of medicine; 2007.

10. Singh A, Misra N. Loneliness, depression and sociability in old age. Ind Psychiatry J 2009; 18(1):51-5.

11. Hawthrone G, Herrman H, Murphy B. Interpreting the WHOQOL-Bref: Preliminary population norms and effect sizes. Soc Indic Res 2006;77(1):37-59.

12. Samulii S, Jaana S, Suvisarri J, Sintonen H, Pirkola $S$, Aromaa A, et al. Impact of psychiatric disorders on health related quality of life. General population survey. Br J Psychiatry 2007;190:326-32.

13. So WK, Marsh G, Ling WM, Leung FY, Lo JC, Yeung $M$, et al. The symptom cluster of fatigue, pain, anxiety, and depression and the effect on the quality of life of women receiving treatment for breast cancer: a multicenter study. Oncol Nurs Forum 2009;36(4):205-14.
14. Polat U, Arpacy A, Demir S, Erdal S, Yalcin S. Evaluation of quality of life and anxiety and depression levels in patients receiving chemotherapy for colorectal cancer: impact of patient education before treatment initiation. J Gastrointest Oncol 2014;5(4):270-5.

15. Engin B, Uguz F, Yilmaz E, Ozdemir M, Mevlitoglu I. The levels of depression, anxiety and quality of life in patients with chronic idiopathic urticaria. J Eur Acad Dermatol Venereol 2008;22(1):36-40.

15. Mystakidou K, Tsilika E, Parpa E, Pathiaki M, Galanos A, Vlahos $L$. The relationship between quality of life and levels of hopelessness and depression in palliative care. Depress Anxiety 2008;25(9):730-6.

16. Imam SMA. Quality of life in patients with major depressive disorder, M Phil Thesis. Bangabandhu Sheikh Mujib Medical University; 2008.

17. Bashar MK. Assessment of quality of life of patients with schizophrenia. FCPS dissertation. Bangladesh College of Physicians and Surgeons; 2009.

18. Ahmed F. Quality of life of patients suffering from obsessive-compulsive disorder. FCPS dissertation. Bangladesh College of Physicians and Surgeons; 2007.

19. World Health Organization. Mental Health Atlas. Geneva: World Health Organization; 2005.

20. Tondo L, Lepri B, Baldessariarini RJ. Reproduction among 1975 Sardinian women and men diagnosed with major mood disorder. Acta Psychiatr Scand 2011;123(4):283-9.

21. Seidman SN, Roose SP, Menza MA, Shabsigh R, Rosen RC. Treatment of erectile dysfunction in men with depressive symptoms: results of a placebo-controlled trial with sildenafil citrate. Am J Psychiatry 2001;158(10):1623-30. 